\title{
CONTORNOS DA (IN)APLICABILIDADE DA TEORIA DO FATO PRINCÍPE NO DIREITO TRIBUTÁRIO
}

\author{
Urá Lobato Martins ${ }^{1}$
}

RESUMO: O artigo analisa a possível aplicabilidade da Teoria Fato do Príncipe no Direito Tributário. A pesquisa foi norteada pelas seguintes questões: o Judiciário pode prorrogar o pagamento de tributos? Qual a posição do Supremo Tribunal Federal sobre a prorrogação do pagamento de tributos pelo Judiciário? É possível aplicar a Teoria Fato do Príncipe no Direito Tributário? Para tanto, serão analisadas decisões judiciais sobre o tema. Utilizou-se o método hipotético-dedutivo, com pesquisa bibliográfica e documental, através de abordagem qualitativa. Para analisar as decisões judiciais, utilizou-se como método de procedimento o método do caso norte-americano.

Palavras-chave: moratória, fato do príncipe, pandemia, separação dos poderes, legalidade.

\section{CONTOURS OF THE (IN) APPLICABILITY OF THE PRINCIPAL FACT THEORY IN}

\section{TAX LAW}

ABSTRACT: The article analyzes the possible applicability of the Prince Fact Theory in Tax Law. The research was guided by the following questions: can the Judiciary extend the payment of taxes? What is the position of the Supreme Federal Court on the extension of the payment of taxes by the Judiciary? Is it possible to apply the Prince Fact Theory in Tax Law? Therefore, judicial decisions on the subject will be analyzed. The hypothetical-deductive method was used, with bibliographical and documentary research, with a qualitative approach. To analyze judicial decisions, the North American case method was used as a procedural method.

Keywords: moratorium, prince fact, pandemic, separation of powers, legality.

\footnotetext{
${ }^{1}$ Doutora em Políticas Públicas e Formação Humana pela UERJ. Mestra em Direitos Humanos pela UFPA. Advogada e Professora Universitária. Avaliadora MEC/INEP. Email: uramartins@ig.com.br.
} 


\section{INTRODUÇÃO}

A pandemia do Covid-19 trouxe consequências para vários setores, considerando que os entes federativos tiveram que seguir as diretrizes da Organização Mundial da Saúde (OMS). Nesse sentido, o lockdown horizontal foi uma medida necessária para conter o avanço da pandemia Covid-19, tendo repercutido na questão tributária. Com relação ao planejamento tributário, a queda na economia gerou, por conseguinte, impacto na arrecadação tributária, ocasionado aumento de despesas, desemprego e caos sociais.

O governo brasileiro adotou algumas medidas para reduzir esse impacto, dentre elas, o Ministério da Economia autorizou que a Procuradoria-Geral da Fazenda Nacional suspendesse os atos de cobrança e facilitasse a renegociação de dívidas; houve concessão de dilatação de prazo para pagamento de tributos federais; ampliação do prazo para a Contribuição Previdenciária sobre a Receita Bruta e Funrural, postergação do prazo de entrega da Declaração de Imposto de Renda, dentre outras medidas.

Dentro dessa nova conjuntura, o Judiciário foi bastante demandando nesse momento da pandemia, tendo sido deferidas algumas liminares em favor dos contribuintes, no sentido de autorizar a prorrogação do prazo de pagamento de tributos.

A questão problemática reside no fato de que o CTN (Código Tributário Nacional), ao tratar do instituto da moratória como modalidade de suspensão da exigibilidade do crédito tributário, determina em seu art. 152 que a prorrogação do pagamento de tributos pode ocorrer em caráter geral ou individual, sendo que o parágrafo único do referido artigo do CTN, determina que "a lei concessiva de moratória pode circunscrever expressamente a sua aplicabilidade à determinada região do território da pessoa jurídica de direito público que a expedir, ou a determinada classe ou categoria de sujeitos passivos."

Nos termos do referido artigo 152, inciso I, do CTN, a moratória em caráter geral pode ser concedida “a) pela pessoa jurídica de direito público competente para instituir o tributo a que se refira"; ou "b) pela União, quanto a tributos de competência dos Estados, do Distrito Federal ou dos Municípios, quando simultaneamente concedida quanto aos tributos de competência federal e às obrigações de direito privado". Caso seja concedida em caráter 
individual, o art. 152, II, do CTN determina que deve ocorrer mediante "despacho da autoridade administrativa, desde que autorizada por lei nas condições do inciso anterior."

Percebe-se, assim, que as hipóteses narradas acima tratam de casos em que o pagamento é prorrogado através de lei, a qual deve especificar, nos termo do art. 153 do CTN, o prazo de duração do favor; as condições da concessão do favor em caráter individual; os tributos a que se aplica; o número de prestações e seus vencimentos; bem como as garantias que devem ser fornecidas pelo beneficiado no caso de concessão em caráter individual.

Sobre a questão, o juiz substituto Rolando Valcir Spanholo, da $21^{\text {a }}$ Vara Federal Cível do Distrito Federal, concedeu liminar em favor de uma determinada empresa, para suspender o recolhimento de quatro tributos, tendo usado como argumento a Teoria do Fato do Príncipe. Em sentido oposto, tiveram decisões judiciais que indeferiram tal pleito, conforme será debatido a seguir. O Supremo Tribunal Federal também se manifestou sobre pleitos que tinham por objeto a prorrogação do pagamento de tributos.

Eis as questões problemáticas: o Judiciário pode interferir no sentido de decidir a prorrogação do pagamento de tributos? Qual a posição do Supremo Tribunal Federal sobre a prorrogação do pagamento de tributos pelo Judiciário? É possível aplicar a Teoria Fato do Príncipe no Direito Tributário? Para responder tais indagações, serão analisados os argumentos contidos em decisões judiciais favoráveis e desfavoráveis sobre a possibilidade de o Judiciário conceder prorrogação de tributos em tempos de pandemia, com foco na fundamentação de tais decisões.

A nível metodológico, utilizou-se o método hipotético-dedutivo, com pesquisa bibliográfica e documental, por meio de abordagem qualitativa. Para a coleta e análise das decisões judiciais, utilizou-se como método de procedimento o método do caso norteamericano (case method) ${ }^{2}$. De acordo com Ramos e Schorscher (2009, p. 49), o método do caso norte-americano "enfatiza mais a fundamentação que embasam a solução proposta do que a resolução do caso em si (...)"

\footnotetext{
2 "O método do caso, na tradição norte-americana, é um instrumento didático que objetiva o ensino de habilidades

voltadas para o desenvolvimento e a prática do raciocínio jurídico por meio de análise de decisões judiciais (...) A

idealização e o pioneirismo da utilização desse método no ensino jurídico são atribuídos a Christopher Columbus Langdell, não por ter inventado o aludido método, mas por tê-lo introduzido no ensino universitário do direito por

meio do estudo e da discussão dos chamados cases em seu curso de contratos na Harvard Law School." (RAMOS;

SCHORSCHER, 2009, p. 49)
} 


\section{TEORIA FATO DO PRÍNCIPE: delimitações conceituais e sua possível aplicabilidade no direito tributário}

No âmbito administrativo, o instituto fato do príncipe consiste na possibilidade de ocorrer uma alteração unilateral de um contrato administrativo. Também pode ocorrer quando medidas administrativas repercutem no sentido de causar um desequilíbrio econômicofinanceiro em detrimento do contrato, tornado inviável o seu cumprimento.

Carvalho Filho (2019) estabelece hipóteses para a inexecução do contrato administrativo sem culpa, que surge quando uma das partes não consegue cumprir o que fora acordado. Uma das hipóteses é justamente o objeto de pesquisa deste artigo, a Teoria Fato do Príncipe. Neste caso, segundo o autor, o desequilíbrio do contrato seria gerado por ato ou medida do próprio Estado, sendo que as condições do contrato seriam alteradas por ato lícito do Estado, provocando, assim, dano ao contratado, diante da oneração excessiva.

Para o referido autor, o fato do príncipe seria "imprevisível, extracontratual e extraordinário". Embora não se destine apenas ao particular, pois esse fato da Administração teria atributo de generalidade, segundo Carvalho Filho (2019).

E qual seria a solução? Para Carvalho Filho (2019), semelhante com o que ocorre com a Teoria da Imprevisão, deveria ocorrer uma revisão do preço, como medida para restaurar o equilíbrio contratual perdido. Também seria possível uma indenização integral, nos casos em que o particular fica impedido, de forma definitiva, a cumprir o contrato.

Para Di Pietro (2019, p. 318), dentre as áleas ou riscos que o particular pode ter quando faz um contrato administrativo, o Fato do Príncipe decorre de "um ato de autoridade, não diretamente relacionado com o contrato, mas que repercute indiretamente sobre ele; nesse caso, a Administração também responde pelo restabelecido do equilíbrio rompido”.

No entanto, Di Pietro entende que tal teoria "somente se aplica se a autoridade responsável pelo fato do príncipe for da mesma esfera de governo em que se celebrou o contrato (União, Estados e Municípios); se for de outra esfera, aplica-se a teoria da imprevisão"”. (DI PIETRO, 2019, p. 320)

\footnotetext{
3 “'́lea econômica, que dá lugar à aplicação da teoria da imprevisão, é todo acontecimento externo ao contrato, estranho à vontade das partes, imprevisível e inevitável, que causa um desequilíbrio muito grande, tornando a execução do contrato excessivamente onerosa para o contratado.” (DI PIETRO, 2019, p. 322)
} 
Para Laubadère (1956), o fato do príncipe seria uma versão lato sensu que existiria quando as condições jurídicas ou de fato foram alteradas no contrato em decorrência por interferência estatal, sendo possível que o contratado seja compensado dos prejuízos que sofreu.

Nessa linha, Dromi (2009) também trata o instituto como possibilidade para gerar o direito à rescisão contratual, configurando algo causado pela atuação estatal, gerando uma impossibilidade definitiva e permanente com relação à execução do contrato e, por conseguinte, o contratado teria direito à indenização.

No direito brasileiro, existe essa previsão do fato do príncipe no âmbito administrativo. GASIOLA (2017, p. 44) ensina que desde o Decreto-Lei ${ }^{\circ}$ 2.300/1986 foi estabelecida a teoria no contrato administrativo.

O Decreto-Lei $n^{\circ}$ 2.300/1986, apesar de introduzir a construção francesa da teoria do contrato administrativo, não faz uso explícito de todas as suas categorias. Com exceção de "equilíbrio econômico-financeiro" (e "fato [excepcional e] imprevisível"), não se lê em todo diploma referência expressa ao "fato do príncipe" ou "fato da Administração". Mesmo assim, com relação ao fato do príncipe, a alteração dos encargos contratuais por atos de caráter geral que repercutam nos preços do contrato estava prevista no art. $55, \S 5^{\circ}$.

A Lei n. 8.666 de 1993, por sua vez, estabelece o Fato do Príncipe como motivo autorizador de alteração contratual:

Art. 65 . Os contratos regidos por esta Lei poderão ser alterados, com as devidas
justificativas, nos seguintes casos:
II - por acordo das partes:
d) para restabelecer a relação que as partes pactuaram inicialmente entre os encargos
do contratado e a retribuição da administração para a justa remuneração da obra,
serviço ou fornecimento, objetivando a manutenção do equilíbrio econômico-
financeiro inicial do contrato, na hipótese de sobrevirem fatos imprevisíveis, ou
previsíveis porém de consequências incalculáveis, retardadores ou impeditivos da
execução do ajustado, ou, ainda, em caso de força maior, caso fortuito ou fato do
príncipe, configurando álea econômica extraordinária e extracontratual. (Redação
dada pela Lei no 8.883 , de 1994)

$\mathrm{O}$ art. 5, III, da Lei 11.079/04 que instituiu normas gerais para licitação e contratação de parceria público-privada no âmbito da administração pública, estabelece que as cláusulas dos contratos de parceria público-privada devem prever "III - a repartição de riscos entre as partes, inclusive os referentes a caso fortuito, força maior, fato do príncipe e álea econômica extraordinária".

Portanto, o dilema existe sobre a aplicação de tal teoria no âmbito do direito tributário, considerando que o instituto deriva de uma relação contratual, quando medidas 
administrativas repercutem no sentido de causar um desequilíbrio econômico-financeiro em detrimento do contrato. Nas próximas linhas, será analisada tal possibilidade.

\section{PROROGAÇÃO DE TRIBUTOS E SEPARAÇÃO DE PODERES}

De fato, a pandemia do COVID-19 impactou vários setores. Em termos de prejuízos arrecadatórios, segundo pesquisa do IBPT - INSTITUTO BRASILEIRO DE PLANEJAMENTO E TRIBUTAÇÃO, havia uma projeção da Arrecadação Tributária de 2020 no sentido de um crescimento de $2,32 \%$ do PIB. Ao analisar a perda em percentual em cada cenário, a pesquisa do IBPT apontou os seguintes dados (2020):

- No Cenário $4^{4}$ a maior perda mensal será no mês de MAIO, equivalente a 44,26\% da arrecadação projetada para o mesmo mês de 2020.

- No Cenário $1^{5}$ a maior perda mensal será no mês de JUNHO, equivalente a $57,85 \%$ da arrecadação projetada para o mesmo mês de 2020.

- No Cenário $2^{6}$ a maior perda mensal será no mês de JULHO, equivalente a 64,37\% da arrecadação total projetada para o mesmo mês de 2020.

- No Cenário $3^{7}$ a maior perda mensal será no mês de AGOSTO, equivalente a 70,57\% da arrecadação projetada para o mesmo mês de 2020.

Segundo dados da Secretaria da Receita Federal (2020), no mês de abril de 2020 já pode ser visualizado um decréscimo real (IPCA) de 28,95\% em relação a abril de 2019. Sendo que "no período acumulado de janeiro a abril de 2020, a arrecadação alcançou o valor de R\$ 502.293 milhões, representando um decréscimo pelo IPCA de 7,45\%.” (SRF, 2020, p. 4)

\footnotetext{
4 "CENÁRIO 4 - Isolamento Social até o Final de Abril. Utilizando-se das premissas já abordadas, com isolamento até 30 de abril, permanecendo em funcionamento somente os serviços e atividades essenciais." (IBPT, 2020, p. 5)

5 "O primeiro cenário foi calculado partindo da premissa que o controle da pandemia obrigará o isolamento social da maior parte da população até o final do mês de maio, permanecendo em operações somente os serviços e atividades essenciais, conforme definidos no Decreto Federal no. 10.282, de 20 de março de 2020" (IBPT, 2020, p. 4)

6 "CENÁRIO 2- Isolamento Social até o Final de Junho. Este cenário parte das mesmas premissas acima, ou seja, que até o final de junho haverá isolamento social, quando em operações somente os serviços e atividades essenciais."

7 "CENÁRIO 3 - Isolamento Social até o Final de Julho. Mesmas premissas anteriores, com isolamento social até 31 de Julho, permanecendo em funcionamento somente os serviços e atividades essenciais." (IBPT, 2020, p. 5)
} 
Nesse sentido, no que se refere às receitas que são administradas pela Receita Federal, “o valor arrecadado, em abril de 2020, foi de R $\$ 93.332$ milhões, representando um decréscimo real (IPCA) de 28,79\%, enquanto que no período acumulado de janeiro a abril de 2020, a arrecadação alcançou R \$ 476.811 milhões, registrando decréscimo real (IPCA) de 7,71\%" (SRF, 2020, p. 4). Para a SRF (2020) esse decréscimo foi resultado da pandemia e, também, decorreu dos diversos diferimentos que totalizaram, aproximadamente, 35 bilhões.

Nesse contexto de pandemia, algumas normas foram editadas com a finalidade de regulamentar a questão. A Lei 13.979, de 07 de fevereiro de 2020, tratou sobre as medidas para enfrentamento da emergência de saúde pública de importância internacional decorrente do coronavírus responsável pelo surto de 2019. Além disso, através do Decreto Legislativo ${ }^{\circ}$ 6, de 20 de março de 2020, o Congresso Nacional reconheceu o estado de calamidade pública, por causa pandemia de COVID-19 declarada pela Organização Mundial de Saúde, com efeitos até 31 de dezembro de 2020.

Assim, alguns Estados e Municípios utilizaram Decretos com a finalidade de regulamentar a questão das medidas de enfrentamento, estipulando horário e normas de proibição temporária de diversos tipos de estabelecimentos, universidades, escolas, etc.

Com efeito, a pandemia do Covid-19 pode ser considerada uma medida administrativa que repercute, considerando a necessidade de imposição de lockdown horizontal, decorrente do estado de calamidade pública. Em tese, estaria presente a figura do ato lícito estatal que gera onerosidade excessiva, ao impedir o prosseguimento de determinadas atividades. No entanto, as relações tributárias estão baseadas no princípio da legalidade, não existe contrato a ser cumprido, mas sim, incidência da lei tributária vigente. Logo, se ocorreu o fato hipotético previsto no antecedente da norma tributária (CARVALHO, 2019), consequentemente, surgirá a obrigação tributária que deverá ser cumprida. Pensar de forma diversa, significaria abrir um precedente no sentido de permitir o não cumprimento de uma obrigação tributária, diante de fatos imprevisíveis e extraordinários.

A prorrogação de tributos é uma possibilidade prevista no CTN, denominada de moratória (modalidade de suspensão da exigibilidade do crédito tributária), que poderia ser usada nesses casos, mas através de ato do Poder Legislativo e não através do Judiciário. A questão é que o CTN, ao tratar do instituto da moratória, determina em seu art. 152, que a prorrogação do pagamento de tributos pode ocorrer em caráter geral ou individual, sendo que o parágrafo único de tal artigo determina que "a lei concessiva de moratória pode 
circunscrever expressamente a sua aplicabilidade à determinada região do território da pessoa jurídica de direito público que a expedir, ou a determinada classe ou categoria de sujeitos passivos."

Logo, o Poder Legislativo é quem deve decidir prorrogar o pagamento de tributos, através de lei, a qual deve especificar, nos termo do art. 153 do CTN, o prazo de duração do favor; as condições da concessão do favor em caráter individual; os tributos a que se aplica; o número de prestações e seus vencimentos; além das garantias que devem ser fornecidas pelo beneficiado no caso de concessão em caráter individual.

Schoueri (2019, p. 671) indica que o uso da moratória é antigo, sendo que no tempo de Constantino, em Roma, o instrumento era utilizado para impedir os credores de exigir a obrigação: "a moratória em matéria tributária era de uso frequente para os casos em que a colheita fosse insuficiente. No período Romano, o Imperador declarava moratória e diferia a cobrança de impostos por alguns anos".

A questão é que o CTN indica que o instituto da moratória depende de lei, sendo que o art. 142 do CTN, ao dispor sobre o lançamento, indica que a cobrança ocorre nos termos da lei, sendo um ato vinculado. Não seria permitido, assim, que o Judiciário interferisse nessa questão.

Para Carvalho (2019, p. 455), considerando o interesse público, "vem à tona o fundamental princípio da indisponibilidade dos bem públicos, razão por que o assunto da moratória há de ser posto em regime de exclusiva legalidade". Este é outro fato, como a incidência tributária tem caráter de indisponibilidade, o Judiciário poderia decidir como e quando tais tributos deveriam ser pagos?

Caliendo (2019, p. 643) assevera que a moratória "é um resultado de um acordo entre o credor e o devedor, por meio de convenção, que autoriza a postergação do adimplemento do crédito tributário, nos termos e condições estabelecidos em lei”. Para o autor, é legítima a necessidade de claros limites legais.

O autor ensina, ainda, que "as razões para a moratória não estavam explicitadas no texto legal, de tal modo que se presume que sejam em razão da dificuldade de solvência por parte do devedor e por favor legal por parte da administração tributária" (CALIENDO, 2019, p. 644). Por considerar que a moratória seria uma espécie de renúncia fiscal, o referido autor entende que sua concessão deveria estar acompanhada da estimativa do impacto orçamentário-financeiro, nos termos da Lei de Responsabilidade Fiscal (Lei Complementar n 
101/2000, art. 14). Neste momento, surge mais um questionamento: o Judiciário tem condições de avaliar o impacto econômico-financeiro para a administração, se houver várias decisões judiciais concedendo prorrogação de tributos?

Para tentar responder tais questões, a seguir serão analisados os argumentos contidos em decisões judiciais favoráveis e desfavoráveis sobre a possibilidade de o Judiciário conceder prorrogação de tributos em tempos de pandemia, com foco na fundamentação de tais decisões.

\section{ANÁLISE DE DECISÕES JUDICIAIS FAVORÁVEIS E DESFAVORÁVEIS NO QUE TANGE À CONCESSÃO DE MORATÓRIA PELO JUDICIÁRIO}

De forma favorável ao contribuinte, o juiz substituto Rolando Valcir Spanholo, da $21^{\text {a }}$ Vara Federal Cível do Distrito Federal, no processo 1016660-71.2020.4.01.3400, concedeu liminar em favor de uma determinada empresa, para suspender o recolhimento de quatro tributos, tendo utilizado como argumento a Teoria do Fato do Príncipe. Segundo o magistrado, considerando a Separação dos Poderes e a exigência no CTN de que a moratória ocorra através de lei, o pedido deveria ser indeferido de plano. Porém, o juiz considerou que em virtude do momento excepcional, a questão ultrapassaria os liames apenas do Direito Tributário.

No caso, o magistrado autorizou de forma excepcional, o diferimento por três meses do recolhimento do IRPJ, CSLL, PIS e COFINS; sem encargo ou penalidade decorrente de tal pagamento prorrogado, bem como concedeu o direito à obtenção de Certidão Positiva com Efeito de Negativa.

Dessa forma, na referida decisão o magistrado fundamentou sua decisão na necessidade de preservar o sistema econômico e social, com base no princípios da dignidade da pessoa humana; valores sociais do trabalho e da livre iniciativa; objetivo constitucional de erradicar a pobreza e a marginalização e reduzir as desigualdades sociais e regionais; bem como os direitos sociais, direitos trabalhistas, dentre outros. Segundo o referido juiz, deveria ocorrer a "preservação da fonte primária de promoção da dignidade das pessoas. No mínimo, até que sejam restabelecidos padrões mínimos de normalidade e/ou até que surjam regras específicas para a preservação da força produtiva nacional frente à pandemia do coronavírus" (JFDF, Processo 1016660-71.2020.4.01.3400, 2020, p. 6) 
Para o magistrado "os atos e relações inerentes ao mundo do Direito Tributário não perdem a sua natureza administrativa e, muito menos, deixam de ser regulados pelas normas estruturantes do ramo do Direito Público ao qual pertencem.” (JFDF, 2020, p. 3)

\begin{abstract}
Abrindo, com isso, a excepcional possibilidade de ser aplicada ao caso em tela a Teoria do FATO DO PRÍNCIPE e, assim, pela via reflexa, alterar parcial (apenas quanto ao momento do pagamento das exações) e momentaneamente (enquanto persistir os efeitos da quarentena horizontal imposta ou até que surja a esperada regulamentação legislativa sobre o tema) a relação jurídica de natureza tributária mantida entre as partes e descrita na exordial, como forma de preservar a própria existência da parte autora e os vitais postos de trabalho por ela gerados. (JFDF Processo 1016660-71.2020.4.01.3400, 2020, p. 4)
\end{abstract}

Para referido o juiz, "em termos práticos, as relações tributárias mantidas entre o fisco e os seus contribuintes não deixam de assumir feição de autênticos contratos de adesão" (JFDF, 2020). Porém, ao contrário do que entendeu o magistrado, não há que se falar em contrato, quando a relação tributária decorre do poder de império e é compulsória, logo, não existe opção de aderir, considerando que a relação tributária está em nível vertical.

Em sentido oposto, em abril de 2020 o presidente do Tribunal de Justiça de São Paulo revogou liminares que tiveram o intuito de prorrogar o vencimento de tributos, por causa da pandemia do COVID-19). Neste caso, o Estado de São Paulo requereu pedido de Suspensão de liminar (Processo n. 2066138-17.2020.8.26.0000), em face dos Juízos de Direito da $6^{\mathrm{a}}$ Vara da Fazenda Pública Comarca de São Paulo, da $8^{\mathrm{a}}$ Vara da Fazenda Pública Comarca de São Paulo, da Vara da Fazenda Pública da Comarca de Presidente Prudente, da $2^{\text {a }}$ Vara da Fazenda Pública Comarca de Osasco, da $1^{\text {a }}$ Vara da Fazenda Pública Comarca de Araraquara.

O presidente do Tribunal de Justiça de São Paulo deferiu o pedido de suspensão com base no potencial de risco de lesão à ordem pública (considerando a irreversibilidade da questão) e pelo fato da moratória ser um instituto que depende de lei. Dessa forma, foi mencionado que "decisão judicial não pode substituir o critério de conveniência e oportunidade da Administração, mormente em tempos de crise e calamidade, porque o Poder

\footnotetext{
${ }^{8}$ Pedido de suspensão dos efeitos das medidas liminares deferidas nos autos dos MANDADOS DE SEGURANÇA n ${ }^{\circ}$ 1016209-67.2020.8.26.0053 (6 $6^{\mathrm{a}}$ Vara da Fazenda Pública da Comarca de São Paulo), $\mathrm{n}^{\mathrm{o}}$ 1017981-65.2020.8.26.0053 ( $8^{\mathrm{a}}$ Vara da Fazenda Pública da Comarca de São Paulo), $\mathrm{n}^{\mathrm{o}}$ 101809771.2020.8.26.0053 ( $8^{\mathrm{a}}$ Vara da Fazenda Pública da Comarca de São Paulo), $\mathrm{n}^{\mathrm{o}}$ 1018234-53.2020.8.26.0053 (8 Vara da Fazenda Pública da Comarca de São Paulo), $\mathrm{n}^{\circ}$ 1005479-68.2020.8.26.0482 (Vara da Fazenda Pública de Presidente Prudente), $\mathrm{n}^{\mathrm{o}}$ 1006496-79.2020.8.26.0405 ( $2^{\mathrm{a}}$ Vara da Fazenda Pública da Comarca de Osasco) e $\mathrm{n}^{\mathrm{o}}$ 1003325-54.2020.8.26.0037 ( $1^{\mathrm{a}}$ Vara da Fazenda Pública da Comarca de Araraquara), sob fundamento de grave lesão à ordem, à economia e à segurança públicas.
} 
Judiciário não dispõe de elementos técnicos suficientes para a tomada de decisão equilibrada e harmônica." (TJSP, 2020, p. 47)

Um fato importante citado pelo presidente do Tribunal de Justiça de São Paulo foi que a prorrogação de pagamento de tributos pode embaraçar e dificultar as funções administrativas, comprometendo, inclusive, medidas necessárias para mitigar dos danos causados pandemia, pois "embora estejam pautadas em efetiva preocupação com o atual cenário mundial, as decisões desconsideraram que a redução na arrecadação dos impostos pelo Estado interfere diretamente na execução das medidas necessárias à contenção da pandemia de COVID-19." (TJSP, 2020, p. 49)

Nesse sentido, o juiz federal convocado Alexandre Rossato da Silva Ávila do Tribunal Regional Federal da $4^{\mathrm{a}}$ Região, ao julgar o Agravo de Instrumento $\mathrm{n}^{\mathrm{o}}$ 501201733.2020.4.04.0000/SC, posicionou-se no sentido de que o Judiciário não teria competência para prorrogar pagamentos de tributos, sob pena de agir como legislador positivo, caracterizando, assim, interferência em outro poder.

\begin{abstract}
Se as empresas integrantes do SIMPLES foram beneficiadas, o Poder Executivo optou por um critério que revela conveniência política, insuscetível de controle pelo Poder Judiciário. É possível, de acordo com interesses econômicos e sociais, estimular e beneficiar determinados setores da economia. Não vejo nisso ofensa aos princípios constitucionais da moralidade pública, da razoabilidade, da proporcionalidade e da capacidade contributiva. Não há similitude de situação que permita invocar o princípio da isonomia (TRF4- Agravo de Instrumento ${ }^{\circ} 5012017$ 33.2020.4.04.0000/SC, 2020, p. 5).
\end{abstract}

Também em sentido contrário, o juiz Emílio Migliano Neto, da $7^{\mathrm{a}}$ Vara da Fazenda Pública de São Paulo, negou liminar para suspender tributos no Processo $n^{\circ} 1018048$ 30.2020.8.26.0053. Para o magistrado, uma liminar nesse sentido agravaria a situação emergencial que vive o município de São Paulo, sofrendo, por conseguinte, a população mais carente.

O que o grupo empresarial impetrante deduziu em sede de liminar é que o Poder Judiciário lhe conceda um verdadeiro "cheque em branco" com prazo de vigência indeterminado, de modo que deixe de recolher seus impostos municipais, especialmente o ISS e IPTU, relativos aos fatos geradores pretéritos e futuros, enquanto perdurar o estado de calamidade pública da saúde decorrente do coronavírus, sem que sejam aplicados juros moratórios e penalidades em face dessa prorrogação. (TJSP, Processo no 1018048-30.2020.8.26.0053, 2020, p. 495)

O magistrado Emílio Migliano Neto entendeu que ocorreria violação do Princípio da Separação de Poderes, caso concedesse a prorrogação do pagamento de tributos. Além disso, 
entendeu que seria inaplicável a adoção da Teoria Fato do Príncipe ${ }^{9}$, por considerar que tal teoria se refere a um contrato administrativo, sendo que o caso objeto da demanda deriva de uma "relação de caráter tributário, vinculante, e não contratual, objeto de negociações e tratativas. O caso sub judice não é de fato de príncipe, pois a pandemia não foi um ato provocado ou só de interesse da administração pública, mas sim um caso de imprevisão." (TJSP, Processo no 1018048-30.2020.8.26.0053, 2020, p. 497)

Eis a questão: a pandemia do COVID-19 pode ser utilizada para afastar a responsabilidade tributária de uma empresa? O desembargador Roger Raupp Rios, presidente da $1^{\text {a }}$ Turma do Tribunal Regional Federal da $4^{\text {a }}$ Região, manteve decisão que negou liminar a uma determinada empresa (Agravo de Instrumento $\mathrm{n}^{\circ}$ 5012834-97.2020.4.04.0000/RS). Para o desembargador, decisões isoladas neste sentido poderiam ter efeito multiplicador e comprometer a governança. Em razão disso, manteve decisão do juízo monocrático, pois entendeu que o Judiciário não teria competência para prorrogar pagamento de tributos, sob pena de agir como legislador positivo, sendo que a moratória também requer lei.

Em razão disso, o desembargador Roger Raupp Rios considerou que seria temeroso aplicar "força maior" como excludente de responsabilidade, devendo ocorrer uma ponderação sobre a consequência disso, já que todos seriam afetados, sendo necessária uma socializar os cursos. Diante disso, a resposta a esta crise não poderia ser desconectada e descontextualizada, sob pena de agravar o risco.

Para Dworkin (2007, p. 39) “as regras são aplicáveis à maneira de tudo-ou-nada. Dados os fatos que uma regra estipula, então ou a regra é válida, e neste caso a resposta que ele fornece deve ser aceita, ou não é válida”. Já os princípios teriam dimensão de peso ou importância.

Eis a questão: o caso objeto de estudo seria um hard case? Entendo que não, pois o CTN já fez a previsão de estado de calamidade como requisito autorizador tanto de Empréstimo Compulsório, como também a possibilidade de ser usado a moratória (critério da discricionariedade e conveniência). $\mathrm{Na}$ ausência de lei autorizando moratória ao caso concreto, não caberia ao Judiciário interferir nesse campo, mesmo porque a pandemia gera perda de arrecadação, o que também pode comprometer o funcionamento do Estado e a viabilidade de políticas públicas necessárias para viabilizar a efetividade dos direitos fundamentais.

\footnotetext{
${ }^{9}$ Para embasar seus fundamentos, o juiz utilizou a doutrina de Laubadère (1956) e Dromi (2009).
} 


\section{POSICIONAMENTO DO STF: análise da Suspensão de Tutela Provisória n. 439} (Ribeirão Preto) e n. 185 (São Luís) e da Suspensão de Segurança de n. 5.373 (Aracaju)

O STF - SUPREMO TRIBUNAL FEDERAL, julgou favorável a STP (Suspensão de Tutela Provisória) n. 439, apresentada pelo Município de Ribeirão Preto, em face de decisão proferida pelo Tribunal de Justiça do estado de São Paulo, que no Agravo de Instrumento $\mathrm{n}^{\circ}$ 2087517-14.2020.8.26.0000, que determinou a suspensão, por três meses, da cobrança de ISS.

No dia 07 de julho de 2020 foi deferida a medida de contracautela "para suspender, liminarmente, os efeitos da decisão proferida nos autos do Agravo de Instrumento $\mathrm{n}^{\mathrm{o}}$ 2087517-14.2020.8.26.0000, em trâmite perante o Tribunal de Justiça paulista, até o trânsito em julgado da ação a que se refere". Sendo que no dia 19 de agosto de 2020 foi confirmada a contracautela, no sentido de suspender os efeitos da decisão proferida nos autos do Agravo de Instrumento $\mathrm{n}^{\mathrm{o}}$ 2087517-14.2020.8.26.0000, do Tribunal de Justiça paulista, até o trânsito em julgado da ação a que se refere.

O Município de Ribeirão Preto alegou que a decisão de suspender o pagamento do tributo acarretaria grave lesão à ordem e à economia públicas, já que ocorreria afetação de uma de suas principais fontes de receita, no caso, o ISS. Além disso, foi destacado o fato da pandemia de COVID-19 também ter impactado a arrecadação do município em questão.

A Procuradoria-Geral da República opinou pelo acolhimento do pedido de suspensão, nos seguintes termos:

SUSPENSÃO DE TUTELA PROVISÓRIA. CONSTITUCIONAL. TRIBUTÁRIO. SUSPENSÃO DE COBRANÇA DO ISS. AUSÊNCIA DE PREVISÃO LEGAL. COVID-19. LESÃO À ORDEM, À ECONOMIA E À SAÚDE PÚBLICAS. IMPACTO NAS FINANÇAS ESTADUAIS E NA EXECUÇÃO DE POLÍTICAS PÚBLICAS. NECESSIDADE DE RECEITA PARA MANUTENÇÃO DOS SERVIÇOS PÚBLICOS ESSENCIAIS. EFEITO MULTIPLICADOR. LIMINAR DEFERIDA. AGRAVO INTERNO. DEFERIMENTO DA CONTRACAUTELA, PREJUDICADO O AGRAVO.

1. Não cabe ao Poder Judiciário se substituir aos gestores responsáveis pela condução administrativa do Estado e decidir quais políticas públicas tributárias hão de ser adotadas no enfrentamento da epidemia da Covid-19, ressalvadas as hipóteses de evidente afronta à ordem constitucional.

2. Há risco de lesão à ordem pública na decisão de Tribunal de Justiça estadual que defere pedido formulado pela Coloproctoclínica Sociedade Simples no sentido de suspender, por três meses, a cobrança do ISS, sem considerar a análise do Executivo acerca da conveniência e oportunidade da dilação do prazo de recolhimento do tributo para o orçamento municipal, em contexto de crise causada pela epidemia de Covid-19, e subvertendo o regime fiscal vigente no município. 
3. A decisão mediante a qual se suspende a cobrança do ISS, com consequente redução na arrecadação do imposto, causa risco de grave lesão à ordem, à economia e à saúde públicas, em razão do grave impacto nas finanças estaduais e do injustificado embaraço na execução das políticas públicas, inclusive de saúde, em contexto de crise causada pela epidemia de Covid-19.

4. O efeito multiplicador de decisões que prorrogam o prazo do recolhimento de tributo municipal, sem amparo legal, reforça a existência do grave risco de lesão à economia pública. - Parecer pelo deferimento da contracautela, prejudicado o agravo interno. (STF, STP 439, 2000, p. 1-2) (grifos nossos)

Evidencia-se, assim, que o MPF não concorda com a interferência do Judiciário sobre a condução administrativa a ser conduzida no momento de pandemia, existindo risco de dilatar prazo de recolhimento de tributos, sem considerar o impacto orçamentário desta medida.

Ao deferir a contracautela, o Min Dias Toffoli argumentou, em síntese, que: determinado segmento não pode ser privilegiado; não cabe ao Poder Judiciário interferir no dever de pagar impostos, nem sobre as políticas públicas a serem adotadas, não sendo possível substituir os gestores responsáveis; através de decisão judicial não pode ser substituído o critério de conveniência e oportunidade que rege a edição dos atos da Administração Pública, considerando que Poder Judiciário não dispõe dos fundamentos técnicos que respaldam uma decisão administrativa.

Nesse sentido, o STF, também concedeu a Suspensão de Tutela Provisória (STP) n. 185, apresentada pelo Município de São Luiz, em face de decisão proferida pelo Tribunal de Justiça do estado do Maranhão, proferida nos autos do Agravo de Instrumento ${ }^{\circ} 0803581$ 39.2020.8.10.0000, que determinou "suspensa a exigibilidade do crédito tributário e autorizar a dilação do recolhimento do Imposto Sobre Circulação de Serviços de Qualquer Natureza ISSQN".

Foi deferida a contracautela em 27 de abril de 2020, sendo confirmada em decisão final no dia 26/08/2020, pois o Min. Toffoli considerou que a decisão objeto da demanda realizou "verdadeira subversão da ordem tributária vigente no estado do Maranhão, e que essa ordem teria o potencial de estender-se a diversas outras empresas, em igual situação tributária, ou mesmo ser replicada para o pagamento de outros tributos". Nos fundamentos, o referido ministro manteve o mesmo critério argumentativo apresentado por ocasião do julgamento da STP n. 439.

Também foi deferida a contracautela em 30 de abril de 2020, nos autos da Suspensão de Segurança n. 5.373, ajuizada pelo Município de Aracaju (SE) contra decisão do Tribunal 
de Justiça do estado de Sergipe, proferida nos autos do Agravo de Instrumento $\mathrm{n}^{\circ} 0003072$ 27.2020.8.25.0000, que determinou a postergação do recolhimento das obrigações tributárias referentes ao ISSQN. Cabe ressaltar esta contracautela foi confirmada em decisão final proferida no dia 06 de agosto de 2020 pelo STF.

Após parecer favorável do MPF, o Min. Dias Toffoli manteve seu posicionamento no de sentido já exposto na Suspensão de Tutela Provisória n. 439 (Ribeirão Preto) n. 185 (São Luís).

\section{CONCLUSÃO}

$\mathrm{Na}$ ausência de lei autorizando a moratória de tributos, não caberia ao Judiciário interferir nesse campo, mesmo porque a pandemia gera perda de arrecadação o que também pode comprometer o funcionamento do estado e a viabilidade de políticas públicas necessárias.

Outrossim, não estaria presente uma hipótese de lacuna da lei, mas sim, existe uma regra clara sobre o assunto que deve ser utilizada na base do tudo ou nada (DWORKIN, 2007). Mesmo se for constatada colisão de princípios, por um lado, a dignidade da pessoa humana, a livre iniciativa, o direito ao trabalho e demais direitos sociais. Em contrapartida, há o princípio da solidariedade que impõe o dever de pagar tributos, para manter a máquina pública em prol da coletividade.

Cumpre ressaltar que situação diferente ocorre ano caso da judicialização das políticas públicas, quando o Judiciário precisa atuar atendendo ao sistema de freios e contrapesos, quando há patente omissão estatal e/ou ilegalidade ou inconstitucionalidade. Mas, no caso da moratória, esta hipótese de suspensão de exigibilidade está dentro da esfera do Legislativo, não cabe ao Judiciário interferir para decidir a forma de moratória, bem como seus prazos, pois isto impactaria na previsão orçamentária e pode inviabilizar, como já dito, a manutenção de serviços básicos, inclusive de saúde, tão essencial neste momento.

O instituto da moratória, inclusive, não gera direito adquirido quando for concedido de forma individual, podendo ser revogada de ofício, nos termos do art. 155 do CTN, quando for descoberto que o beneficiado não satisfazia ou deixou de satisfazer as condições ou não cumprira ou deixou de cumprir os requisitos para a concessão do favor. Caso o Judiciário conceda moratória, como seriam fixados essas condições e prazos? Eis o dilema. 
Através das decisões proferidas pelo Min Dias Toffoli nos julgamentos mencionados alhures, fica claro que somente o gestor deve decidir sobre questões de pagamentos de tributos, considerando que o Judiciário não deve adentrar no critério de conveniência e oportunidade. Conceder privilégio a determinadas empresas que ingressam no Poder Judiciário poderia acarretar danos ainda maiores.

Conforme Parecer do MPF nas referidas ações (Suspensão de Tutela Provisória n. 439 e n. 185 e na Suspensão de Segurança de n. 5.373), o Judiciário não deve interferir na condução administrativa a ser conduzida no momento de pandemia, existindo risco de dilatar prazo de recolhimento sem considerar o impacto orçamentário. Sendo destacado no parecer do MPF o efeito multiplicador de tais decisões, existindo, assim, possibilidade de grave dano de lesão à economia.

Considerando que cada ente federativo tem sua própria previsão orçamentária e foi impactado pela pandemia com a queda da arrecadação, o Judiciário acabaria prejudicando a continuidade de políticas públicas em andamento, bem como outros custos necessários em prol da coletividade, considerando que efetivar direitos requer custos.

Por amor ao debate, embora tenha certa coerência uma decisão que decida prorrogar um tributo, considerando o atual contexto, a questão precisa ser analisada considerando o todo e não apenas uma parte. Pensando em termos coletivos, precisaria analisar o impacto de decisões que acarretem queda de arrecadação, o que poderia inviabilizar o enfrentamento da pandemia, inclusive.

No que tange à aplicação da Teoria do Fato do Príncipe, conforme exposto, o dilema reside sobre a aplicação de tal teoria no âmbito do direito tributário, considerando que o instituto deriva de uma relação contratual, quando medidas administrativas repercutem no sentido de causar um desequilíbrio econômico-financeiro em detrimento do contrato. Ocorre que a relação tributária decorre de um ato impositivo e é compulsória, visa atender ao interesse público, estando presente, assim, o princípio da indisponibilidade, razão pela qual a moratória ser concedida em regime de exclusiva legalidade, consoante ensina Carvalho (2019).

A quarentena horizontal impactou em vários setores, mas isto não significa que nosso sistema permite alteração na relação tributária, razão pela qual a Teoria do Fato do Príncipe somente poderia usar esta justificativa da pandemia no âmbito de uma relação contratual. Não pode se falar em contrato, quando a relação tributária decorre do poder de império e é 
compulsória, logo, não existe opção de aderir, considerando que a relação tributária está em nível vertical, independe da vontade do contribuinte.

Pensar de forma contrária, significaria abrir um precedente e subverter a lógica tributária, conforme ressaltou o Min. Dias Toffoli na STP n. 185, no sentido de permitir que o Judiciário interfira sobre uma questão que impactará o orçamento e as políticas públicas que devem ser implementadas e mantidas por cada ente federativo.

Portanto, o Judiciário somente pode interferir quando houver uma lesão à ordem legal e/ou constitucional, mas não deve implementar um instituto tributário que somente pode ser instituído por lei que deverá especificar seus requisitos, condições e prazos específicos.

\section{REFERÊNCIAS}

CALIENDO, Paulo. Curso de Direito tributário. 2 ed. São Paulo: Editora Saraiva, 2019.

CARVALHO FILHO, José dos Santos. Manual de Direito Administrativo. $33^{a}$ edição. São Paulo: Atlas, 2019.

CARVAlHO, Paulo de Barros. Curso de Direito Tributário. 30 ed. São Paulo: Saraiva, 2019.

DI PIETRO, Maria Sylvia Zanella. Direito Administrativo, 32 a edição. Rio de Janeiro: Forense, 2019.

DROMI, Roberto. Derecho Administrativo. 12 ed. Argentina: Ciudad Argentina Editorial de Ciência y Cultura, 2009.

DWORKIN, Ronald. Levando os direitos a sério. Trad. de Nelson Boeira. 2. ed. São Paulo: Martins Fontes, 2007.

IBPT - INSTITUTO BRASILEIRO DE PLANEJAMENTO E TRIBUTAÇÃO. Queda da arrecadação tributária em decorrência dos efeitos da pandemia do coronavírus. 2020.

JFDF - JUSTIÇA FEDERAL DO DISTRITO FEDERAL. Processo 101666071.2020.4.01.3400. Brasília, 26 de março de 2020 .

GASIOLA, Gustavo Gil. Fato da Administração: uma revisão bibliográfica. REVISTA DIGITAL DE DIREITO ADMINISTRATIVO, vol. 4, n. 2, p. 39-68, 2017.

LAUBADÈRE, André de. Traité théorique et pratique des contrats administratifs Imprenta: Paris, Libr. Generale de Droit et de Jurisprudence, 1956. 
RAMOS, Luciana de Oliveira; SCHORSCHER, Vivian Cristina. Método de Caso. In: GHIRARDI, José Garcez (Coord.). Método de ensino em Direito: conceitos para um debate. São Paulo: Saraiva, 2009.

SRF - SECRETARIA DA RECEITA FEDERAL. Análise da Arrecadação das Receitas $\begin{array}{llllll}\text { Federais } & - & \text { Abril } & \text { de } & 2020 . & \text { Disponível }\end{array}$ http://receita.economia.gov.br/dados/receitadata/arrecadacao/relatorios-do-resultado-daarrecadacao/arrecadacao-2020/abril2020/analisemensal-abr-2020.pdf

SCHOUERI, Luís Eduardo. Direito tributário. 9 ed. São Paulo: Editora Saraiva, 2019.

STF - SUPREMO TRIBUNAL FEDERAL. Suspensão de Tutela Provisória n. 439. Relator(a): Min. Presidente DIAS TOFFOLI, julgamento: 19/08/2020, Publicação: 24/08/2020. Brasília, 2020.

STF - SUPREMO TRIBUNAL FEDERAL. Suspensão de Tutela Provisória n. 185. Relator(a): Min. Presidente DIAS TOFFOLI, julgamento: 26/08/2020, Publicação: 31/08/2020. Brasília, 2020.

STF - SUPREMO TRIBUNAL FEDERAL. Suspensão da Segurança n. 5373. Relator(a): Min. Presidente DIAS TOFFOLI, julgamento: 06/08/2020, Publicação: 12/08/2020. Brasília, 2020.

TJSP - TRIBUNAL DE JUSTIÇA DE SÃO PAULO. Pedido de Suspensão de liminar Processo n. 2066138-17.2020.8.26.0000. São Paulo, 08 de abril de 2020.

TJSP - TRIBUNAL DE JUSTIÇA DE SÃO PAULO. Mandado de Segurança, Processo no 1018048-30.2020.8.26.0053. São Paulo, 06 de abril de 2020.

TRF4 - TRIBUNAL REGIONAL FEDERAL DA 4 REGIÃO. Agravo de Instrumento no 5012017-33.2020.4.04.0000/SC. Rio Grande do Sul, 27 de março de 2020.

TRF4 - TRIBUNAL REGIONAL FEDERAL DA 4 REGIÃO. Agravo de Instrumento $\mathbf{n}^{\mathbf{0}}$ 5012834-97.2020.4.04.0000/RS. Rio Grande do Sul, 16 de abril de 2020. 